The most useful

learning resource for

all MRCP(UK) exams

and beyond. A must-

\title{
Medical Masterclass
}

\section{Third edition textbooks now available}

\section{Choose the package or subscription that's best for you.}

\section{Printed textbooks}

The 12 printed textbooks cover the scientific background to medicine; common clinical presentations; planning a strategy for investigation and treatment; and the medical specialties that are covered in the MRCP(UK) exams.

The third edition of Medical Masterclass, is full of new content to aid your learning.

\section{Website subscriptions}

Buy the best website subscription for you, depending on the date of your exam.

Monthly subscriptions are available, and you can choose between access to MRCP(UK) Part 1 and Part 2 exam questions.

\section{The premier package}

The complete package gives you the full set of 12 printed textbooks and 1 year of unlimited access to the Medical Masterclass website.
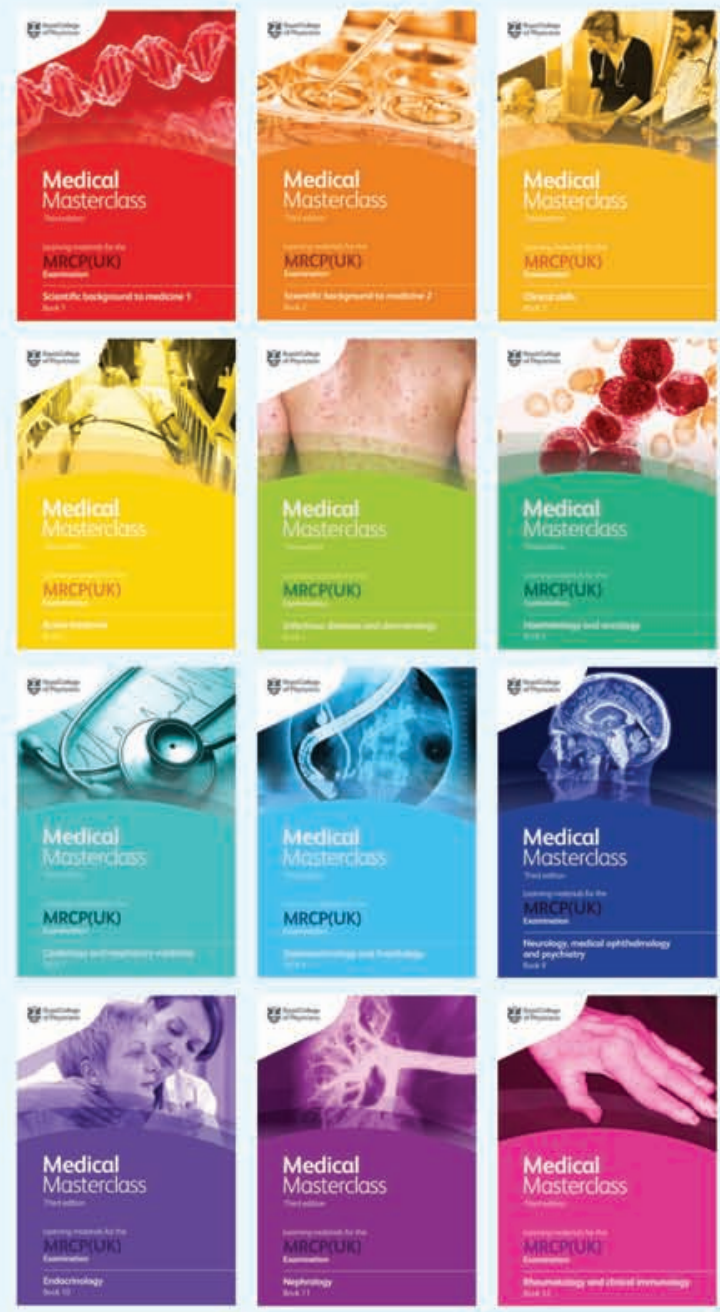


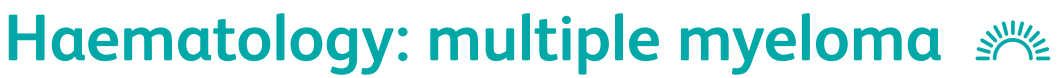

\author{
Authors: Medical Masterclass contributors; edited by John Firth ${ }^{\mathrm{A}}$
}

\section{Aetiology/pathophysiology}

Multiple myeloma (MM) is characterised by the accumulation of clonal, malignant plasma cells in the bone marrow. The cause of myeloma is unknown. Radiation may be a factor in some cases (although there is no association with therapeutic radiation). Exposure to industrial/agricultural toxins or viruses have all been considered, but proof is lacking. Chromosomal abnormalities have been identified, most commonly involving the immunoglobulin heavy chain switch region (on the long arm of chromosome 14), although these do not appear to be enough on their own to give rise to MM. The tumour cells within the bone marrow are supported by a non-malignant population of stromal cells that produce cytokines (eg interleukin-6) that enhance myeloma cell growth and prevent apoptosis.

\section{Epidemiology}

MM accounts for about $10 \%$ of haematological malignancies. The annual incidence in the UK is 5 per 100,000. Black people are affected twice as commonly as white people, and males more than females. The median age for diagnosis is 65 years, with fewer than $3 \%$ of patients presenting when they are younger than 40 years.

\section{Clinical presentation}

\section{Common}

$>$ bone pain and pathological fractures

$>$ anaemia (bone marrow failure)

$>$ recurrent infections (due to immunoparesis)

$>$ hypercalcaemia

> renal failure (multiple aetiologies: hypercalcaemia, light chain deposition, non-steroidal drugs, anaemia, infections)

> abnormal bleeding (due to platelet dysfunction)

\section{Rare}

> hyperviscosity syndrome (ischaemia, heart failure and neurological problems)

> amyloid disease (eg carpal tunnel syndrome)

\section{Investigations}

If myeloma is suspected, the following tests may be useful.

> FBC can reveal normochromic, normocytic anaemia.

\footnotetext{
A Extract from Medical Masterclass (third edition, 2018) produced by the Royal College of Physicians and written by over 75 authors and contributors, under the editor-in-chief Dr John Firth
}

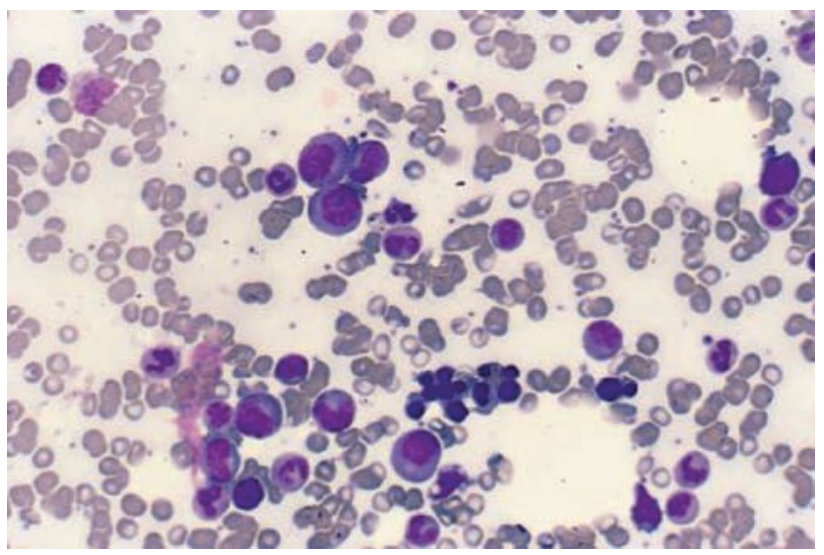

Fig 1. Myeloma cells. This bone marrow shows a number of different types of cell. The larger cells with eccentric nuclei and basophilic cytoplasm are myeloma cells. Note the perinuclear transparency that represents the Golgi apparatus.

> Erythrocyte sedimentation rate (ESR) is raised (the positive charge of the protein neutralises the negative charge of sialic acid on the erythrocyte membrane, reducing their natural tendency to repulse each other and causing the cells to fall faster in a column).

> Biochemistry can show raised calcium (usually with a normal alkaline phosphatase) and renal impairment.

> Serum electrophoresis may demonstrate a monoclonal protein. This is an immunoglobulin (Ig)G or IgA in most cases, but can be any class of Ig. Reduced levels of normal immunoglobulins are supportive.

> Excess serum free light chains, either kappa or lambda, may be demonstrated in the serum (sometimes the plasma cell clone is making only light chains).

> The diagnosis of myeloma depends on demonstrating increased plasma cells (>10\%) in the bone marrow (Fig 1).

> Skeletal survey X-rays may demonstrate lytic lesions (Fig 2).

\section{Staging (the International Staging System)}

Staging (the International Staging System (ISS)) relates to levels of albumin and the protein $\beta_{2}$-microglobulin (Table 1).

\section{Table 1. Staging of myeloma (ISS).}

$\begin{array}{lll}\text { Stage } 1 & \text { Stage } 2 & \text { Stage } 3 \\ \beta_{2} \text {-microglobulin } & \text { Neither } 1 \text { nor } 3 & \beta_{2} \text {-microglobulin }>5.5 \mathrm{~g} / \mathrm{dL} \\ <3.5 \mathrm{mg} / \mathrm{dL} & & \\ \text { Albumin }>35 \mathrm{~g} / \mathrm{L} & & \end{array}$




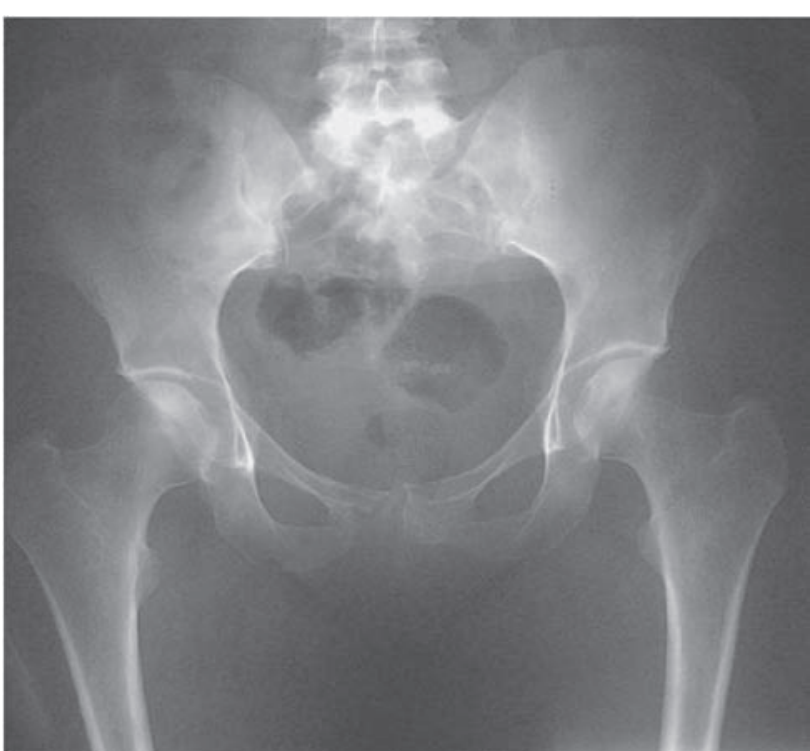

Fig 2. Myeloma of bone. Note that the symphysis pubis has been eroded by myeloma. There are no apparent deposits in the upper femurs or pelvis.

\section{Differential diagnosis of a serum paraprotein}

\section{Malignant}

$>$ Waldenström's macroglobulinaemia

$>$ lymphoma

$>$ chronic lymphocytic leukaemia

$>$ primary amyloidosis

> plasma cell leukaemia

\section{Benign/stable}

$>$ monoclonal gammopathy of uncertain significance

$>$ AIDS

\section{Treatment}

Myeloma may present as an acute emergency:

> acute kidney injury: prompt treatment of volume depletion is critical; involve the nephrologists early

> hypercalcaemia: fluids and bisphosphonates are critical

$>$ spinal cord compression: a radiotherapy emergency

> hyperviscosity: consider plasmapheresis.

Specific treatment depends on a number of factors such as comorbidities and the presence of poor prognostic factors (see below). There is no known cure for myeloma, but in recent years the treatments for it have improved dramatically. Many patients may now achieve a stable remission, lasting a number of years, through a combination of chemotherapy and autologous stem-cell transplantation.

Most haematologists will participate in trials, ensuring standard treatment for patients and access to drugs which may be otherwise unavailable (ie are funded for patients who are on trials).

\section{Chemotherapy}

Chemotherapy treatment, in combination with steroids, is the mainstay of treatment in newly diagnosed patients. Many new treatments have been developed in the past 10-15 years including thalidomide and lenalidomide (the mechanism of action of which is still under investigation but possibly anti-angiogeneic) and bortezomib (a proteasome inhibitor). Toxicities of these drugs include thromboembolic events and peripheral neuropathy. These regimens can be given as pulsed therapy (ie repeated at regular time intervals), either orally or as subcutaneous injections. The response rates are high: some patients enter complete remission, but most enter a 'plateau phase' with a lower but steady paraprotein. All patients will eventually relapse. More intensive regimens are used in younger and fitter patients, and these can be used to debulk disease prior to transplantation.

\section{Autologous stem-cell transplantation}

The safety of these procedures now means that they have become applicable to a larger number of patients. Many haematologists would consider patients up to the age of 70 as eligible for autologous transplants as part of their first line of treatment (ie debulk with chemotherapy first, but proceed directly to transplant thereafter). This depends on the overall condition of the patient and their response to chemotherapy. Second autologous transplants may also be performed, often with good results.

\section{Allogeneic stem-cell transplantation}

This is only an option for a minority of patients, particularly those who are young, fit and have a human leukocyte antigen-matched sibling (or well-matched unrelated) donor. Response rates are high, but unfortunately relapse is common.

\section{Maintenance therapy}

Lenalidomide is used as maintenance therapy after relapse, to help prolong remission. Toxicities include venous thromboembolism (so anticoagulation is often prescribed to prevent this), cramp and cytopenias.

\section{Plasmapheresis}

Plasma viscosity may provide an indication for plasmapheresis but clinical features are far more important. Evidence of critical ischaemia, neurological syndrome or coma may improve following this intervention.

\section{Supportive care}

Hypercalcaemia should be managed with fluids and bisphosphonates initially. Bisphosphonates should be continued on a monthly basis, even with a normal calcium level, as there is a suggestion that they may reduce bony disease and modulate the disorder.

Pain is common in myeloma and often requires opiate analgesia plus NSAIDs. Radiotherapy may be helpful in controlling pain due to localised bony lesions. 
Recurrent blood transfusions and antibiotics may be required as a result of both the disease and the treatment. In patients who have recurrent infections, prophylactic infusions of intravenous immunoglobulins may be considered.

\section{Psychological support}

The patient will almost certainly need some help in coming to terms with the diagnosis. Try to involve family or friends, particularly when first explaining the situation. Societies exist for support and information, and the patient should be given access to these.

\section{Prognosis}

Median survival with chemotherapy is about $3-5$ years. A high ISS stage (see above) correlates with a poor prognosis. 